\title{
DIREITOS DAS CRIANÇAS E ADOLESCENTES E POLÍTICAS PÚBLICAS: UMA ANÁLISE DO PROJETO "POLÍTICAS PÚBLICAS PARA CRIANÇAS E ADOLESCENTES EM SITUAÇÃO DE RUA DE RIBEIRÃO PRETO - SP”
}

\section{Mariana Albuquerque $\operatorname{Zan}^{1}$ Camilo Zufelato ${ }^{2}$}

RESUMO: O presente trabalho se propõe a analisar o Projeto "Políticas públicas para crianças e adolescentes em situação de rua de Ribeirão Preto - SP". Desenvolvido a partir da formação de um Grupo de Trabalho (GT) intersetorial composto por Secretarias Municipais, serviços e instituições locais que atuam junto de crianças e adolescentes em situação de rua, o Projeto busca realizar diálogos e arranjos capazes de aperfeiçoar a rede de proteção local, bem como contribuir no planejamento de uma política pública que atenda e garanta direitos do público infanto-juvenil que se encontra nas ruas de Ribeirão Preto.

Palavras-chave: Políticas públicas. Crianças e adolescentes em situação de rua. Intersetorialidade.

\section{CHILDREN AND ADOLESCENTS' RIGHTS AND PUBLIC POLICIES: AN ANALYSIS OF THE PROJECT "PUBLIC POLICIES FOR STREET CHILDREN AND ADOLESCENTS IN RIBEIRÃO PRETO - SP"}

\begin{abstract}
This paper aims to analyze the Project "Public Policies for street children and adolescents in Ribeirão Preto - SP". Developed from the formation of an intersectoral working group (WG) composed of municipal departments, services and local institutions that work with children and adolescents living on the streets, the project seeks to carry out dialogues and arrangements capable of improving the local protection network, as well as contribute to the planning of a public policy that meets and guarantees the rights of children and youth who are on the streets of Ribeirão Preto.
\end{abstract}

Keywords: Public policies. Children and adolescents in street situation. Intersectoriality.

\section{INTRODUÇÃO}

O presente trabalho tem por escopo apresentar o Projeto "Políticas públicas para crianças e adolescentes em situação de rua de Ribeirão Preto - SP” e, a partir dele, pensar o grupo de crianças e adolescentes em situação de rua como titular de direitos coletivos, bem como elencar alguns dos pontos chaves para a estudo e elaboração de uma política pública para o referido grupo. A vivência na rua é marcada pela marginalização dos sujeitos,

\footnotetext{
1 Mestranda pelo Programa de Pós-Graduação em Direito da Faculdade de Direito de Ribeirão Preto da Universidade de São Paulo. E-mail de contato: mzan@usp.br. Currículo Lattes: http://lattes.cnpq.br/8054593404829454.

2 Professor Associado da Faculdade de Direito de Ribeirão Preto da Universidade de São Paulo. E-mail de contato: camilo@usp.br. Currículo lattes: http://lattes.cnpq.br/3975939347414439.
} 
acarretando o declínio da sociabilidade, a reversão das identidades, fraturas e rupturas do vínculo social e quebra das redes sociais de suporte (FIORATI, 2014, p.1460).

Nesse contexto, a exclusão social deve ser entendida não como uma incapacidade de desenvolvimento de condutas adaptativas, mas sim como a falta de acessibilidade aos bens materiais e imateriais produzidos pela sociedade, bem como a submissão a uma condição existencial marcada por violências, desigualdades e violação de direitos fundamentais. Garantir o acesso a direitos à crianças e adolescentes em situação de rua consiste em um autêntico direito coletivo, haja vista a consagração pelo Estado brasileiro na Constituição Federal de 1988 (CF/88) da dignidade da pessoa humana como um de seus fundamentos (art. $1^{\circ}$, III, CF/88) e, dentre seus objetivos, a erradicação da pobreza e da marginalização e a redução das desigualdades sociais e regionais (art.3º III, CF/88) (BRASIL, 1988). Ademais, o Estatuto da Criança e do Adolescente (ECA) representa um significativo avanço no próprio entendimento de infância e juventude, bem como na consolidação de direitos para esses sujeitos.

O Projeto "Políticas públicas para crianças e adolescentes em situação de rua de Ribeirão Preto - SP”, ainda em desenvolvimento, teve seu início na Pré-Conferência Regional de Ribeirão Preto da Defensoria Pública do Estado de São Paulo, em agosto de 2017, momento no qual a sociedade civil apontou e elegeu a temática "crianças e adolescentes em situação de rua" como a prioritária para a atuação da Defensoria Pública de Ribeirão Preto para o ano de 2018. A partir de então, foi formado um Grupo de Trabalho (GT) intersetorial composto por Secretarias Municipais, serviços e instituições locais que atuam junto de crianças e adolescentes em situação de rua, a fim de buscar diálogos e arranjos capazes de aperfeiçoar a rede de proteção local, bem como contribuir no planejamento de uma política pública que atenda esse público infanto-juvenil.

É neste contexto que o presente trabalho se insere na busca e análise de pontos chaves para o estudo e elaboração de uma política pública que seja apta para atender demandas de crianças e adolescentes em situação de rua, bem como efetivar direitos desse grupo que se encontra constantemente sofrendo violências, exclusões e opressões.

\section{OBJETIVOS}

Como objetivos, o presente trabalho busca: a) descrever o Projeto "Políticas públicas para crianças e adolescentes em situação de rua de Ribeirão Preto - SP", apresentando seu histórico e contexto de surgimento e desenvolvimento; b) traçar um panorama jurídico do 
grupo de crianças e adolescentes em situação de rua como titular de direitos coletivos; e c) propor alguns dos pontos chaves para a estudo e elaboração de uma política pública para o referido grupo.

\section{METODOLOGIA}

Como proposta metodológica, trata-se de uma pesquisa sociojurídica, de cunho qualitativo, no formato de estudo de caso, tendo por objeto de análise o Projeto "Políticas públicas para crianças e adolescentes em situação de rua de Ribeirão Preto - SP”. Como material de análise, são utilizados os dados provenientes de levantamentos bibliográficos, atas das reuniões do GT do Projeto e diário de campo elaborado.

\section{DESENVOLVIMENTO DE PESQUISA}

Neste tópico, será tratado o desenvolvimento da pesquisa construída até o presente momento, de forma a serem apresentados o histórico do Projeto "Políticas públicas para crianças e adolescentes em situação de rua de Ribeirão Preto - SP”, os marcos normativos de direitos de crianças e adolescentes, ressaltando o grupo infanto-juvenil que se encontra nas ruas e, por fim, os pontos que foram identificados até o momento como cruciais para o estudo e para a elaboração de uma política pública para crianças e adolescentes que encontram em situação de rua.

\subsection{PROJETO "POLÍTICAS PÚBLICAS PARA CRIANÇAS E ADOLESCENTES EM SITUAÇÃO DE RUA DE RIBEIRÃO PRETO - SP"}

A partir da contextualização histórica, pretendo justificar o porquê da escolha do Projeto como estudo de caso da presente pesquisa. Além disso, importância desse tópico reside em demonstrar quais os caminhos e metodologias foram adotados desde seu início e durante seu desenvolvimento, para que possibilite uma análise que leve em consideração as particularidades, as facilidades e os obstáculos encontrados a partir das escolhas feitas.

Neste ponto, importante frisar que, estando o Projeto ainda em desenvolvimento, todos os conteúdos por ora estudados, analisados e aqui neste texto apresentados não buscam trazer respostas e propor parâmetros inquestionáveis para a elaboração de uma política pública para crianças e adolescentes em situação de rua. Por outro lado, a proposta é trazer as etapas realizadas pelo Projeto e pela pesquisa até o presente momento, de forma que seja possível fazer uma ação-reflexão dos caminhos que foram e serão percorridos. Assim, a 
apresentação do histórico do Projeto torna-se parte fundamental para a compreensão de todo o deslinde do trabalho.

Antes de iniciar a apresentação do histórico do Projeto, para compor um panorama de Ribeirão Preto, alguns dados mostram-se relevantes. Trata-se de município localizado no interior do estado de São Paulo, estando a noroeste da capital paulista, com território de $650,916 \mathrm{~km}^{2}$. Segundo o censo realizado em 2019, sua população é de 604.682 pessoas e a densidade demográfica de 928,92 habitantes por quilometro quadrado (hab/km²) (IBGE, 2019). Em relação ao trabalho e rendimento, no ano de 2018, o salário médio mensal era de 2,9 salários mínimos e a porcentagem de pessoas ocupadas em comparação à população total era 39\%. No que se refere a domicílios com rendimentos mensais de até meio salário mínimo por pessoa, a porcentagem era de $27,8 \%$ da população nessas condições. Em 2017, o Produto Interno Bruto (PIB) per capita era de $\mathrm{R} \$ 51.759,84$ (IBGE, 2019). Em 2010, a taxa de escolarização de 6 a 14 anos era de 96,9\%, não havendo informações mais recentes acerca dessa taxa (IBGE, 2019). Por fim, no que diz respeito ao território e ambiente, em 2010, a porcentagem de domicílios com esgotamento sanitário adequado era $98,4 \%$, a porcentagem de domicílios urbanos em vias públicas com arborização era de 92,5\% e a porcentagem de domicílios urbanos em vias públicas com urbanização adequada (calçada, pavimentação, bueiros e meio-fio) era de 64,5\% (IBGE, 2019).

Passando agora ao Projeto, seu histórico encontra-se estritamente ligado ao papel institucional da Defensoria Pública, tendo em vista que seu início ocorreu na Pré-Conferência da Regional de Ribeirão Preto da Defensoria Pública do Estado de São Paulo, em agosto de 2017. Seus contornos específicos foram definidos com a posterior abertura de Procedimento Administrativo Coletivo pelas Defensorias Públicas locais com atribuição para atuação na defesa dos direitos de crianças e adolescentes. No contexto da Pré-Conferência, havendo um plexo de demandas de diferentes graus de complexidade trazidas pela sociedade civil no que tange à área da infância e juventude, tornou-se necessário definir prioridades, momento no qual os defensores públicos da Vara da Infância e Juventude sugeriram que fosse apontada uma demanda prioritária para a atuação da Defensoria Pública para o ano seguinte.

Com isso, foi apontada a necessidade da instituição despender esforços para as demandas de crianças e adolescentes em situação de rua, haja vista ser uma população invisibilizada no que diz respeito à efetivação de direitos, ao acesso a serviços e às políticas públicas, ao passo que também consiste em um grupo que é alvo constante de violências, seja 
por parte do Estado, seja por parte da sociedade. Neste contexto, a temática "crianças e adolescentes em situação de rua" foi eleita como prioritária para atuação da unidade da Defensoria Pública de Ribeirão Preto em 2018. Trazer tais informações mostra-se relevante na medida em que se buscou garantir a indispensável participação popular no processo de escolhas de prioridades da instituição, seja a nível macro, na determinação de objetivos para o plano de atuação enquanto foco primordial das Conferências Estaduais, seja também a nível micro, apontando aos defensores que atuam diretamente com crianças e adolescentes as demandas mais sensíveis e prioritárias do ponto de vista da população da região.

Além disso, a temática escolhida no contexto da Pré-Conferência encontra-se intimamente relacionada às próprias atribuições da Defensoria Pública, a qual, com fundamento no artigo 134 da Constituição Federal de $19885^{3}$, no artigo $5^{\circ}$, inciso VI, alínea 5 , “c" $"$ e inciso XII ${ }^{5}$, da Lei Complementar n ${ }^{\circ}$ 988/2006, e nos artigos $3^{\circ}$-A, inciso III ${ }^{6}$, e $4^{\text {o }}$, incisos I, III, VII, XI e XXII ${ }^{7}$, todos da Lei Complementar $n^{\circ}$ 80/1994, consiste na instituição do sistema de justiça encarregada da defesa, judicial e extrajudicial, das pessoas hipossuficientes. Escolhida a temática de crianças e adolescentes em situação de rua, foi instaurado o Procedimento Administrativo Coletivo, iniciado com a abertura de Edital para seleção de interessados e interessadas em realizar serviço voluntário junto à Defensoria Pública de Ribeirão Preto, bem como com a elaboração do Plano de Ação do Projeto.

\footnotetext{
3 Art. 134. A Defensoria Pública é instituição permanente, essencial à função jurisdicional do Estado, incumbindo-lhe, como expressão e instrumento do regime democrático, fundamentalmente, a orientação jurídica, a promoção dos direitos humanos e a defesa, em todos os graus, judicial e extrajudicial, dos direitos individuais e coletivos, de forma integral e gratuita, aos necessitados, na forma do inciso LXXIV do art. $5^{\circ}$ desta Constituição Federal.

${ }^{4}$ Art. $5^{\circ}$ - São atribuições institucionais da Defensoria Pública do Estado, dentre outras: [...] VI - promover: c) a tutela individual e coletiva dos interesses e direitos da criança e do adolescente, do idoso, das pessoas com necessidades especiais e das minorias submetidas a tratamento discriminatório;

${ }^{5}$ Art. $5^{\circ}$ - São atribuições institucionais da Defensoria Pública do Estado, dentre outras: [...] XII - contribuir no planejamento, elaboração e proposição de políticas públicas que visem a erradicar a pobreza e a marginalização e a reduzir as desigualdades sociais;

${ }^{6}$ Art. $3^{\circ}$-A. São objetivos da Defensoria Pública: [...] III - a prevalência e efetividade dos direitos humanos.

${ }^{7}$ Art. $4^{\circ}$ São funções institucionais da Defensoria Pública, dentre outras: [...] I - prestar orientação jurídica e exercer a defesa dos necessitados, em todos os graus; III - promover a difusão e a conscientização dos direitos humanos, da cidadania e do ordenamento jurídico; VII - promover ação civil pública e todas as espécies de ações capazes de propiciar a adequada tutela dos direitos difusos, coletivos ou individuais homogêneos quando o resultado da demanda puder beneficiar grupo de pessoas hipossuficientes; XI - exercer a defesa dos interesses individuais e coletivos da criança e do adolescente, do idoso, da pessoa portadora de necessidades especiais, da mulher vítima de violência doméstica e familiar e de outros grupos sociais vulneráveis que mereçam proteção especial do Estado; XXII - convocar audiências públicas para discutir matérias relacionadas às suas funções institucionais.
} 
O Edital de Serviço Voluntário - Área Infância e Juventude nº 01/2017, datado de 31 de agosto de 2017 e publicado no Diário Oficial em setembro do mesmo ano, tinha como objetivo selecionar pessoas voluntárias para: a) incentivar a participação da sociedade na atuação cotidiana da Defensoria Pública do Estado de São Paulo, em Ribeirão Preto, na área da Infância e Juventude; b) fortalecer e aprimorar a capacidade operativa da Defensoria Pública do Estado de São Paulo, em Ribeirão Preto, na área da Infância e Juventude; c) promover estudos quanto à previsão legal de políticas públicas voltadas para crianças e adolescente em situação de rua; d) promover levantamento das políticas públicas existentes em Ribeirão Preto e voltadas para crianças e adolescente em situação de rua; e) e avaliar as políticas públicas levantadas, sua pertinência e sua adequação às diretrizes nacionais e internacionais. É justamente nesse ponto do histórico do Projeto que ele se torna o objeto de estudo da pesquisa.

O Plano de Ação elaborado para o Projeto apontava para o objetivo de diagnosticar as necessidades da rede local no tocante ao atendimento de crianças e adolescentes em situação de rua, delimitando medidas para a estruturação dos serviços. A premissa basilar do Plano de Ação consistiu na necessidade de incluir o tema na agenda pública municipal, avançando nas discussões, a fim de se chegar a ações práticas no campo das políticas públicas. Nesse sentido, desde o início do Projeto, foi identificado um desafio no que tange à capacitação e ao envolvimento dos profissionais de diversos níveis da gestão pública, seja o profissional que atua na ponta da rede de atendimento e que lida diretamente com esta criança ou adolescente, seja o gestor das políticas públicas municipais que deve estruturar uma rede de atendimento para tanto, por meio da criação ou aprimoramento de políticas públicas. A especificidade do tema, bem como a carência de serviços específicos, também surgem como desafios importantes nesse contexto.

Sendo verificada uma forte demanda entre os atores da rede local de proteção por políticas públicas voltadas a crianças e adolescentes em situação de rua em suas mais diversas peculiaridades (educação, assistência social, saúde, convivência familiar e comunitária), a ideia basilar do Plano de Ação consistiu na tentativa de responder a três demandas, quais sejam: dar visibilidade às crianças e adolescentes em situação de rua de Ribeirão Preto; trazer ao debate público a necessidade de políticas públicas específicas para esse grupo; e qualificar e/ou criar uma política pública que atenda, a nível local, a demanda específica de crianças e adolescentes em situação de rua. Como objetivo geral, o Plano de Ação estabelece a análise 
das políticas públicas municipais de atendimento a crianças e adolescentes em situação de rua, a fim de compreender e buscar diálogos e articulações capazes de aperfeiçoar a rede de proteção local, com base nas diretrizes nacionais e internacionais e em experiências exitosas de outros municípios e, por fim, contribuir na proposição e planejamento de uma nova política pública que atenda crianças e adolescentes em situação de rua do município.

Dentre alguns de seus objetivos específicos do Plano de Ação, destacamos: a) Levantamento e análise das normativas nacionais e internacionais sobre políticas públicas para crianças e adolescentes em situação de rua, incluindo as portarias do Conselho Nacional de Assistência Social (CNAS) e do Conselho Nacional dos Direitos da Criança e do Adolescente (CONANDA); b) Levantamento e análise das experiências exitosas de outros municípios na implementação de redes locais de proteção que atendam às peculiaridades deste público; c) Análise das políticas públicas já existentes no município de Ribeirão Preto para atendimento de crianças e adolescentes em situação de rua; d) Realização de um seminário em Ribeirão Preto para discussão das peculiaridades e necessidades de uma rede de proteção que busque atender de maneira adequada crianças e adolescentes em situação de rua em seus mais diversos aspectos (saúde, educação, convivência familiar, entre outros); e) Realização de uma audiência pública em Ribeirão Preto para apresentação dos dados coletados e das análises realizadas no primeiro momento do projeto, e para escuta da população e da rede de proteção sobre as dificuldades no atendimento a este público, bem como as necessidades que visualizam para que se tenha um atendimento efetivo; f) Com base em todas as informações colhidas, verificação da necessidade e conveniência de se firmar Termo de Ajustamento de Conduta (TAC) ou propor Ação Civil Pública (ACP) em face do município.

Elaborado o Plano de Ação e selecionados os voluntários, a primeira etapa do trabalho consistiu no levantamento dos marcos conceituais e das principais normas nacionais e internacionais que dizem respeito à proteção desse grupo social. Além disso, foram estudadas algumas experiências exitosas de políticas públicas dedicadas a crianças e adolescentes implementadas no país. A nível local, foram realizadas visitas a serviços já existentes na cidade, quais sejam, ONG Dona Nair, Serviço de Acolhimento Institucional para Crianças e Adolescentes em Situação de Vulnerabilidade e Risco Social (SAICA), Programa de Erradicação do Trabalho Infantil (PETI), Conselho Tutelar, Centro de Atenção Psicossocial Infantil (CAPS i), a fim de conhecer melhor a realidade de atores que trabalham direta ou indiretamente com o público em questão. 
No dia 29 de junho de 2018, conforme um dos objetivos específicos do Plano de Ação, aconteceu a Audiência Pública "Políticas públicas para crianças e adolescentes em situação de rua de Ribeirão Preto - SP" na Câmara Municipal da cidade, que contou com a presença de diversas autoridades. Nesta oportunidade, foram apresentados todos os dados coletados na fase inicial do Projeto e ouvidas a população e a rede de proteção sobre as possibilidades e dificuldades no atendimento a crianças e adolescentes em situação de rua. Nessa mesma ocasião, partindo dos encaminhamentos e da necessidade de articulação entre os serviços municipais que atuam junto a crianças e adolescentes, foi organizado um Grupo de Trabalho (GT) para se dedicar à discussão da temática de crianças e adolescentes em situação de rua, tendo a seguinte composição: Secretarias Municipais de Assistência Social, Educação, Esporte, Saúde e Cultura, bem como representante da Guarda Civil Municipal, do Conselho Municipal dos Direitos da Criança e do Adolescente (CMDCA), Conselho Tutelar, representante do Educandário, dos Serviços de Fortalecimento de Vínculos e Liberdade Assistida, pelo Sistema de Justiça e pelo Núcleo de Atendimento Integrado (NAI). Também visando atender aos apontamentos da Audiência Pública, foi realizada apresentação de todo o projeto ao CMDCA objetivando maior aproximação com o Conselho de Direitos.

As reuniões do GT, realizadas mensalmente, começaram a ocorrer em setembro de 2018 e tiveram por escopo inicial a apresentação de todos os serviços oferecidos a crianças e adolescentes de um modo geral, a fim de que todos os componentes do GT se apropriassem da existência e funcionamento dos serviços disponíveis no Município, bem como para possibilitar o mapeamento de serviços que atuam ou poderiam atuar, isolada ou conjuntamente, no atendimento de crianças e adolescentes que se encontram especificamente em situação de rua.

As reuniões de apresentação aconteceram até abril de 2019 e, com base nas discussões levantadas pelos próprios componentes do GT, nas atas das reuniões e de informações disponibilizadas nas apresentações dos serviços, foi elaborado o Relatório Diagnóstico do Projeto "Políticas Públicas para Crianças e Adolescentes em Situação de Rua de Ribeirão Preto", redigido pelos voluntários que atuam junto à Defensoria Pública. O Relatório contém os serviços existentes no Município, as questões de maior destaque no tocante à temática de crianças e adolescentes em situação de rua em Ribeirão Preto e as respectivas justificativas. 
O Relatório Diagnóstico é dividido da seguinte maneira: inicialmente, foi apresentado um breve histórico sobre o Projeto e quais os caminhos haviam sido percorridos até o momento da produção do documento; posteriormente, a partir da análise das atas por nós redigidas em todas as reuniões do Projeto, foram identificadas as principais questões trazidas pelos integrantes do GT no que tange à educação, saúde, assistência social, conselhos, esporte/cultura e sistema de justiça. Além das questões, a partir das atas, foi feito um trabalho de identificação das justificativas que sustentam tais questões, a fim de facilitar na proposição de possíveis ações para solucionar ou mitigar as respectivas questões.

Apresentado o Relatório para o GT, este continuou se reunindo mensalmente, todavia, superada a fase das apresentações do serviço, as reuniões passaram a ter por objetivo a análise das questões elencadas no Relatório como principais e a consequente discussão de ações possíveis a curto, médio ou longo prazo por meio de vias vislumbradas como adequadas pelo GT. Definidas as ações no âmbito do GT, os defensores públicos com atribuição para atuação na defesa dos direitos e crianças e adolescentes reuniram-se com as agentes do Centro de Atendimento Multidisciplinar (CAM) e com os voluntários do Projeto para definição dos passos seguintes, tendo em vista a efetivação das ações a curto prazo elencadas. A fim de garantir a continuidade e coesão do trabalho, as ações foram categorizadas em: fluxos, ofícios, reuniões e outros, sendo estas últimas de caráter residual.

É, pois, nesse contexto de desenvolvimento de um projeto que visa elaborar e implementar uma política pública para crianças e adolescentes em situação de rua em Ribeirão Preto que o presente trabalho se insere e busca compreender crianças e adolescentes em situação de rua como um grupo titular de direitos coletivos e busca estudar e analisar pontos chaves para a elaboração de uma política pública que garanta direitos a esse grupo em específico.

\subsection{CRIANÇAS E ADOLESCENTES EM SITUAÇÃO DE RUA COMO GRUPO TITULAR DE DIREITOS COLETIVOS}

A relevância da temática sobre população em situação de rua, especialmente crianças e adolescentes, fundamenta-se, dentre outras razões, na necessidade de trazermos ao debate a alta vulnerabilidade social em que essa população se encontra, estando constantemente sujeita a violações de direitos fundamentais. Ainda que pessoas em situação de rua possam integrar uma zona de assistência, formar uma rede social entre os pares na mesma condição e pessoas 
que oferecem ajuda ocasional, é evidente que se encontram em situação de flutuação na tessitura social e povoam seus interstícios sem encontrar um lugar designado e reconhecido (FIORATI, 2014). Nesse contexto, a exclusão social deve ser entendida não como uma incapacidade de desenvolvimento de condutas adaptativas, mas sim como a falta de acessibilidade aos bens materiais e imateriais produzidos pela sociedade e como a submissão a uma condição existencial marcada por violências, injustiças e desigualdades.

A ampliação do conceito de pobreza, em razão da perspectiva da exclusão e da vulnerabilidade, contexto em que crianças e adolescentes em situação de rua encontram-se, coloca-nos diante de uma realidade multifacetada de carências e privações, as quais se sustentam reciprocamente e que produzem e reproduzem um sistema de pobreza crônica (CARNEIRO, 2005). Assim, coloca-se como central a discussão acerca da elaboração de políticas públicas que efetivem um plexo de direitos que é negado a crianças e adolescentes em situação de rua e de políticas que atendam, dada a complexidade da vulnerabilidade em questão, uma série de peculiaridades da vivência na rua. Como por exemplo, uma política pública que estabeleça a construção de abrigos a fim de efetivar o direito à moradia, uma extensão eficiente do sistema de saúde pública para a realização do direito à saúde e outras medidas políticas que assegurem o respeito ao princípio da dignidade da pessoa humana (ZUFELATO, 2016).

Garantir o acesso a direitos à população em situação de rua, incluindo, pois crianças e adolescentes, consiste em um autêntico direito coletivo, haja vista que a consagração pelo Estado brasileiro consagrou na Constituição Federal de 1988 (CF/88) como um de seus fundamentos a dignidade da pessoa humana (art.1 ${ }^{\circ}$, III, CF/88) e, dentre seus objetivos, a erradicação da pobreza e da marginalização e a redução das desigualdades sociais e regionais (art.3º, III, CF/88) (BRASIL, 1988). Nesse sentido, deve, ainda, ser ressalvado um aspecto relevante no que diz respeito à construção e implementação de políticas públicas para pessoas em situação de rua, sobretudo crianças e adolescentes. Para além de visarem a garantia e efetivação de direitos, tais políticas devem ser pensadas de modo a não estabelecerem condutas repressivas, o que resultaria em tentativa de molde de comportamento desconsiderando aquele da vivência de rua e, principalmente, em uma homogeneização violenta (LEITE, 2017).

O fenômeno das populações em situação de rua apresenta diversas determinações, como a precarização ou o rompimento total das relações de trabalho formal e dos vínculos 
familiares e comunitários. Esses fatores conduzem à perda de suporte familiar, comunitário e da identidade social de trabalhador e à sobrevivência em condições de desabrigo, o que resulta em uma condição de sobrevivência sub humana. A situação de rua tende a se estabelecer já na adolescência e juventude, em grupos sociais em situação de pobreza extrema e que apresentam altos índices de vulnerabilidade social (FIORATI, 2014).

Em se tratando do público infanto-juvenil, a denominação "criança e adolescente em situação de rua" caracteriza-se por ser, atualmente, a mais utilizada para a designação de grupos de crianças e adolescentes que, de alguma maneira, têm a rua como seu referencial. Importante ressalvarmos, nesse ponto, que a ida para as ruas não implica necessariamente na ruptura dos vínculos familiares: crianças e adolescentes que ainda permanecem com alguns vínculos passam a integrar uma zona de vulnerabilidade, ao passo que, o afrouxamento desses vínculos, seu futuro rompimento e o estreitamento com a vivência de rua podem culminar na desfiliação e fixação na rua enquanto ambiente definitivo de suas atividades e moradia (GONTIJO; MEDEIROS, 2009).

Essa denominação escolhida, além de ser atualmente a mais adotada, abarca um amplo espectro de possibilidades, meios e sentidos do "estar na rua" (RIZZINI, 2019). Além disso, a expressão "situação de rua" enfraquece a ideia predominante e pejorativa dada ao termo "de rua" e evidencia as potencialidades de mudanças nos estilos de vida das crianças e adolescentes, não lhes negando o papel ativo em suas próprias vidas. A invisibilização dessas crianças e adolescentes, na maioria das vezes, inicia-se em âmbito familiar e comunitário. A ida pela rua pode sinalizar, portanto, um pedido de socorro. Porém, a rua, tornando-se um espaço de referência, de moradia, de trabalho infantil, de exploração sexual somada à fragilização dos vínculos com a família e com a comunidade, coloca-os em uma posição de extrema vulnerabilidade, na qual violações de direitos são constantes e acentuadas (RIZZINI, 2019).

No contexto internacional, a Convenção sobre os Direitos das Crianças (1989) consiste no primeiro instrumento legal internacional a estabelecer um plexo de direitos humanos para crianças e adolescentes, direitos estes indispensáveis ao desenvolvimento integral da infância e adolescência, tais como direitos civis, políticos, sociais, econômicos, culturais, tendo exercido grande influência no processo de elaboração do Estatuto da Criança e do Adolescente de 1990 (ECA/1990) (RIZZINI, 2019). 
A promulgação da $\mathrm{CF} / 88$, e, posteriormente, a substituição do Código de Menores de 1927 (reformulado em 1979) pelo ECA representaram uma relevante mudança de paradigma no entendimento sobre a proteção de crianças e adolescentes e, consequentemente, a compreensão da temática de crianças e adolescentes em situação de rua pela ótica, principalmente, do direito ${ }^{8}$. Considerada como uma das leis mais avançadas do mundo voltadas à infância e à juventude, o ECA assegura o status de sujeitos de direitos a crianças e adolescentes, superando a visão fundamentada apenas nas suas vulnerabilidades e rompendo com a noção de crianças e adolescentes enquanto modelo deficitário de pessoas pautado por aquilo que lhes falta e não pelo que desejam (MELO, 2011). Essa mudança representou, pois, uma desvinculação do discurso das necessidades de crianças e adolescentes a partir das experiências do mundo adulto para a compreensão desse grupo a partir de seus próprios interesses, conferindo-lhes graus de protagonismo e o reconhecimento de suas subjetividades jurídicas (MELO, 2011).

A Política Nacional para a População em Situação de Rua, estabelecida pelo Decreto $n^{\circ} .7053 / 2009$, ainda que não tenha por foco apenas crianças e adolescentes em situação de rua, constitui um marco no que diz respeito ao compromisso do Estado brasileiro em garantir direitos a essa população, bem como representa uma conquista para os movimentos sociais que disputaram e ainda disputam políticas para o referido grupo, sobretudo o Movimento Nacional da População de Rua (RIZZINI; VALE; COUTO, 2018). Importante destacarmos que a Política Nacional para a População em Situação de Rua é estruturada em dois eixos principais, quais sejam: verticalidade federativa e interdisciplinaridade e intersetorialidade nas ações direcionadas à população em situação de rua. Esses dois eixos representam uma preocupação da política em atender as demandas de indivíduos que, embora tenham a rua como fator comum e local de referência, caracterizam-se pela heterogeneidade e pela multiplicidade de demandas. Além disso, esses eixos demonstram a necessidade da atuação de diferentes setores do Poder Público em articulação com a sociedade civil para a efetividade da política (RIZZINI; VALE; COUTO, 2018).

Para além dos avanços trazidos pela referida política, no que diz respeito à população infantil e adolescente em situação de rua, algumas lacunas podem ser identificadas.

\footnotetext{
${ }^{8}$ Embora a CF/88 bem como o ECA sejam importantes marcos para o ordenamento jurídico e, portanto, são referências para o âmbito do direito, as disposições trazidas por eles não abarcam único e exclusivamente questões jurídicas, impactando, no que diz respeito à questão de crianças e adolescentes em situação de rua, as áreas da saúde, assistência social, educação, cultura, entre outras.
} 
Inicialmente, em termos de agenda política nacional, a temática de crianças e adolescentes em situação de rua passou a ganhar mais força em meados dos anos 2000 (RIZZINI; VALE; COUTO, 2018), evidenciando uma omissão dos Poderes Públicos frente à realidade dessas crianças e adolescentes. A partir de 2005, em âmbito do CONANDA, teve início uma mobilização para a elaboração de uma política nacional voltada exclusivamente para crianças e adolescentes em situação de rua.

Nesse contexto, entre os anos de 2005 e 2010, foi criada e promovida a campanha nacional "Criança não é de Rua", a qual, por meio de visitas às capitais dos estados para a identificação, contato e articulação com instituições atuantes junto a crianças e adolescentes em situação de rua, teve por objetivo criar estratégias para a elaboração de uma política nacional. Como um dos resultados dessa campanha, em sede da Secretaria de Direitos Humanos da Presidência da República (SDPH) juntamente com instituições da sociedade civil foi instituída a Rede Nacional de Atenção à Criança e ao Adolescentes em Situação de Rua em 2013. A esta coube, a partir de um processo de escuta da sociedade civil, a elaboração de diretrizes e recomendações para o atendimento de crianças e adolescentes em situação de rua, documento este intitulado "Subsídios para elaboração de uma política nacional para crianças e adolescentes em situação de rua".

Importante apresentarmos tal histórico, a fim de destacarmos os avanços conquistados no tocante aos direitos das crianças e adolescentes em situação de rua, avanços esses recentes e obtidos em razão de mobilizações sociais em diferentes instâncias. Contudo, no contexto brasileiro, ainda que a $\mathrm{CF} / 88$ e o ECA representem um significativo avanço para os direitos das crianças e adolescentes, bem como para o entendimento sobre infância e juventude, no que diz respeito àqueles que se encontram em situação de rua, há um histórico de sistemáticas violações de direitos e garantias formalmente previstos, razão pela qual o planejamento e execução de políticas públicas para a efetivação de direitos desse grupo consistem em medida imprescindível. Nesse contexto, a busca por pontos que sejam cruciais para o estudo e para a elaboração de uma política pública o grupo infanto-juvenil em situação de rua mostra-se necessária para a compreensão, em termos legais, dos serviços que devem ser prestados, das metodologias a serem utilizadas para um atendimento adequado e integral e dos direitos a serem garantidos. Ademais, a construção de um arcabouço legal consiste em uma necessidade frente à elaboração de uma política pública que esteja dentro dos parâmetros 
legais e possibilita a identificação de serviços e agentes para o fortalecimento da rede de atendimento de crianças e adolescentes em situação de rua.

\subsection{PONTOS CHAVES PARA O ESTUdO E ELABORAÇÃO DE UMA POLÍTICA PÚBLICA PARA CRIANÇAS E ADOLESCENTES EM SITUAÇÃO DE RUA}

Nesse tópico, a identificação de pontos chaves a partir da análise dos referidos marcos normativos mostra-se importante para o desenvolvimento do Projeto "Políticas públicas para crianças e adolescentes em situação de rua em Ribeirão Preto - SP” e para a presente pesquisa, uma vez que consistem em fio condutores para a revisão bibliográfica e para a construção de parâmetros de políticas públicas para crianças e adolescentes em situação de rua.

\subsubsection{Dados quantitativos e qualitativos}

A existência ou inexistência de dados quantitativos e qualitativos acerca da população de crianças e adolescentes em situação de rua, seja a nível nacional, estadual ou municipal, consiste em uma informação basilar para a elaboração de uma política pública. Quantificar numericamente esse público caracteriza-se como uma tarefa fundamental para a organização, a distribuição territorial e a divisão de atribuições dos serviços. Já a colheita de dados qualitativos, tais como, sexo, gênero, idade, raça/etnia, razões para estar na rua, se houve rompimento dos vínculos familiares, atividades desenvolvidas na rua, locais onde mais frequenta, entre outros, são dados imprescindíveis para o planejamento de uma política pública que atenda as demandas de tais crianças e adolescentes.

No município de Ribeirão Preto, não há quaisquer dados sobre as crianças e adolescentes em situação de rua. Assim, a falta de dados consiste em um dado em si: não há uma preocupação do Poder Público local em desenvolver atividades, fornecer serviços específicos, evitar os vazios socioassistenciais e, consequentemente, garantir o acesso a direitos a esse público vulnerabilizado. Em termos estaduais e nacionais, também não há informações precisas e tampouco dados quantitativos e qualitativos sobre crianças e adolescentes em situação de rua. Nesse contexto, no âmbito do Projeto, diante da inexistência de dados locais sobre esse grupo de crianças e adolescentes, as discussões e debates dependeram da contribuição de educadores, assistentes sociais, conselheiras/os tutelares, técnicos e demais membras/os do GT que atuam cotidianamente com esse público. A inexistência de dados oficiais confirma a invisibilidade desse público, evidencia a dificuldade 
que encontramos no que tange à avaliação dos impactos de políticas públicas existentes para esse grupo específico e obstaculiza o planejamento de políticas adequadas e integrais, capazes de efetivar direitos (BRASIL, 2017).

Esse item coloca-nos diante do cenário nacional, no qual, apenas em 2016, a partir da Resolução Conjunta CNAS/CONANDA n ${ }^{\circ} 1$ de 15 de dezembro de 2016, foi estabelecido um conceito legal de crianças e adolescentes em situação de rua, a fim de servir como vetor para a atuação do Poder Público e a total ausência de dados sobre a população em situação de rua, mais o público infanto-juvenil. O Comentário Geral nº $21 / 2017^{9}$ da ONU prevê como obrigação dos Estados a produção e sistematização de dados sobre crianças e adolescentes em situação de rua.

Em igual sentido, a Lei Estadual $n^{\circ} 16.544 / 2017^{10}$ determina como um dos objetivo do Estado de São Paulo na Política Estadual de Atenção Específica para a População em Situação de Rua a produção, sistematização e disseminação de dados sobre a população em situação de rua. Embora não seja expressa a referência ao público infanto-juvenil, dada a prioridade estabelecida a nível constitucional para políticas voltadas a crianças e adolescentes,

\footnotetext{
${ }^{9}$ Data collection and research: 23. In partnership with academia, civil society and the private sector, States should develop systematic, rights-respecting, participatory mechanisms to collect data and share disaggregated information about children in street situations. States must ensure that the collection and use of such information does not stigmatize or harm these children. Collecting data on children in street situations should be integrated into national data collection on children, ensuring that national data do not rely solely on household surveys, but also cover children living outside household settings. Children in street situations should participate in setting the aims and agendas of research and in gathering information, analysing and disseminating research to inform policymaking, and designing specialized interventions. Street situations change rapidly, and research needs to be carried out periodically to ensure policy and programmes are up to date. Tradução livre: Recolha de dados e investigação: 23. Em parceria com o meio académico, a sociedade civil e o sector privado, os Estados deveriam desenvolver mecanismos sistemáticos, respeitadores dos direitos e participativos para recolher dados e partilhar informação desagregada sobre crianças em situações de rua. Os Estados devem assegurar que a recolha e utilização de tais informações não estigmatize ou prejudique estas crianças. A recolha de dados sobre crianças em situação de rua deve ser integrada na recolha de dados nacionais sobre crianças, assegurando que os dados nacionais não se baseiem apenas em inquéritos domiciliários, mas abranjam também as crianças que vivem fora do contexto familiar. As crianças em situação de rua devem participar na definição dos objetivos e agendas da investigação e na recolha de informação, análise e divulgação da investigação para informar a formulação de políticas, e na concepção de intervenções especializadas. As situações de rua mudam rapidamente, e a investigação deve ser realizada periodicamente para assegurar a atualização das políticas e programas.

${ }^{10}$ Artigo $5^{\circ}$ - São objetivos da Política Estadual de Atenção Específica para População em Situação de Rua:

[...] III - produzir, sistematizar e disseminar dados e indicadores sociais, econômicos e culturais sobre a presença dessa população e a rede de cobertura de serviços públicos à população em situação de rua em todo o Estado, suas regiões e nos municípios paulistas;

IV - produzir, sistematizar e disseminar dados estatísticos quantitativos e qualitativos sobre a população em situação de rua incluída ou não nos serviços públicos em todo o Estado, suas regiões e nos municípios paulistas; $\mathrm{V}$ - incentivar e contribuir com a pesquisa, produção e a divulgação de conhecimento sobre a população em situação de rua em todo o Estado, suas regiões e municípios paulistas.
} 
irrazoável desconsiderarmos que tal objetivo não englobe ou até mesmo não dê primazia à colheita de dados sobre crianças e adolescentes em situação de rua.

\subsubsection{Orientações metodológicas específicas}

Tendo em vista o contexto em que crianças e adolescentes em situação de rua se encontram, as diversas e constantes violações de direito a que são expostos, o pouco ou nenhum acesso a serviços, a fragilidade e a iminência de ruptura dos laços familiares e parentais, são necessárias orientações metodológicas específicas para o atendimento desse público. Tais orientações metodológicas têm por finalidade garantir que as/os profissionais possam atuar visando um atendimento integral sob uma abordagem garantidora de direitos, em oposição a uma ação repressiva ou de salvamento e total desconsideração das demandas e opiniões das crianças e adolescentes.

Nesse sentido, para além do respeito à dignidade, a não discriminação, o interesse superior da criança e o direito da criança a ser guiada no exercício dos seus direitos pelos prestadores de cuidados, pais e membros da comunidade (ONU, 2017), orientações essas comuns ao desenvolvimento de programas junto a crianças e adolescentes, os fios condutores específicos para essa atuação consistem na aproximação gradativa, na construção de vínculos de confiança, na atenção personalizada, na socialização de informações sobre os serviços disponíveis, bem como direitos, na garantia de acesso a serviços que considerem as singularidades desse público e no respeito à individualidade de cada criança e adolescente (BRASIL, 2017).

Tratam-se, pois, de orientações indispensáveis para o desenvolvimento de atividades e projetos que visem a garantia de direitos de crianças e adolescentes em situação de rua. No contexto do Projeto, a necessidade de haver um atendimento orientado por uma metodologia própria para crianças e adolescentes em situação de rua caracterizou-se como uma demanda comum a todos os serviços, sobretudo àqueles ligados à área da Saúde, à Assistência social e aos Conselhos Tutelares, serviços esses que comumente estabelecem o primeiro contato com as crianças e adolescentes em situação de rua. Haja vista tais orientações já se encontrarem formalmente estabelecidas, sendo que, no âmbito da assistência social, há uma resolução específica prevendo diretrizes políticas e metodológicas para o atendimento de crianças e adolescentes em situação de rua, outro ponto chave diz respeito à formação e capacitação de profissionais que atuam com esse público para que essas orientações possam ser conhecidas, disseminadas, debatidas e seguidas no âmbito dos mais diversos serviços. 
3.4.3 Formação de profissionais que trabalham junto de crianças e adolescentes em situação de rua

A formação e a capacitação de profissionais que atuam junto de crianças e adolescentes em situação de rua caracteriza-se, se não o mais importante, um dos pontos principais estabelecidos nos marcos normativos. Nesse sentido, a Resolução Conjunta CNAS/CONANDA $n^{\circ} 1 / 2017^{11}$ prevê o fomento da capacitação continuada dos profissionais do SUAS que estejam em contato com crianças e adolescentes em situação de rua. Dada a importância e centralidade dos serviços socioassistenciais para a rede de atendimento desse grupo, indispensável que tais profissionais sejam preparados e formados para uma abordagem integral e em consonância com os direitos das crianças e adolescentes. O Comentário Geral $\mathrm{n}^{\circ} 21$ da $\mathrm{ONU}^{12}$ destaca o papel dos Estados nos investimentos, bem como na facilitação de formações e capacitações para os profissionais e demais interessados que, direta ou indiretamente, tenham contato com crianças e adolescentes em situação de rua. Aqui, desenha-se a capacitação básica de boa qualidade enquanto uma obrigação dos Estados para a garantia de direitos das crianças e adolescentes.

A Lei Estadual $n^{\circ} 16.544$, em igual sentido, traz a formação e capacitação dos profissionais a partir de diretrizes também definidas na lei como um dos objetivos da Política Estadual de Atenção Específica para a População em Situação de Rua, a fim de que seja possível uma melhora na oferta dos serviços, bem como para que os direitos da população em situação de rua sejam respeitados. No âmbito do GT do Projeto, a capacitação contínua dos

\footnotetext{
${ }^{11}$ Art. $1^{\circ}$. Estabelecer as seguintes Diretrizes Políticas e Metodológicas para o atendimento de crianças e adolescentes em situação de rua no âmbito da Política de Assistência Social: [...] XXIX - fomentar a educação continuada dos diversos profissionais do SUAS que trabalhem com crianças e adolescentes, em situação de rua, considerando suas especificidades, cultura e linguagem e o papel fundamental desta relação no atendimento (BRASIL, 2017).

${ }^{12}$ Os Estados devem investir em formação básica de boa qualidade inicial, tanto formação inicial como permanente, sobre direitos das crianças, proteção da infância e o contexto local das crianças em situação de rua, para todos os profissionais que possam entrar em contato direto ou indireto com crianças em situação de rua, em áreas como a elaboração de políticas, aplicação da lei, justiça, educação, saúde, trabalho social e psicologia. Esta formação pode recorrer à perícia de atores não estatais e deve ser integrada nos currículos das instituições de formação relevantes. [...] A formação básica e especializada deve incluir mudanças de atitude e de comportamento, bem como transferência de conhecimentos e desenvolvimento de competências, e deve encorajar a cooperação e colaboração intersetorial. Os governos nacionais e locais devem compreender e apoiar o papel crítico dos trabalhadores sociais, incluindo os trabalhadores de rua, na detecção precoce, fornecendo apoio às famílias com crianças em risco e às crianças em situações de rua. Os profissionais devem ser envolvidos no desenvolvimento participativo de procedimentos operacionais, diretrizes de boas práticas, diretivas estratégicas, planos, normas de desempenho e códigos disciplinares, e devem receber apoio para os implementar na prática. Os Estados devem facilitar a sensibilização e formação de outros interessados que entram em contato direto ou indireto com crianças em situação de rua, tais como trabalhadores dos transportes, representantes dos meios de comunicação social, líderes comunitários e espirituais/religiosos e atores do setor privado, que devem ser encorajados a adotar os Direitos da Criança e os Princípios Empresariais (ONU, 2017).
} 
profissionais caracterizou-se como das questões mais trazidas e abordadas: no que diz respeito a todas as secretarias e serviços apresentados, a capacitação dos profissionais para trabalhar junto a esse público em específico coloca-se como uma ação a ser realizada para garantir o atendimento de crianças e adolescentes e, consequentemente, a efetivação de direitos desse grupo.

No que diz respeito à implementação de políticas públicas voltadas às pessoas em situação de rua, incluindo, pois, o grupo de crianças e adolescentes, os atores responsáveis a fazem dentro de uma lógica de individualização do problema, caracterizando os sujeitos enquanto culpados e gerando ainda mais discriminação social, não contextualizando a situação de rua vinculada aos determinantes socioeconômicos, históricos, políticos e culturais na raiz de uma sociedade produtora de desigualdades sociais (FIORATI et al., 2016, p.7).

Assim, temos a formação e a capacitação contínua como um tema chave para elaboração de uma política pública, uma vez que consiste em medida necessária para a realização de trabalhos, atividades e projetos junto de crianças e adolescentes em situação de rua, dado o contexto de vulnerabilidade em que se encontram, contexto este ainda mais acentuado em razão da cultura higienista e repressora e do distanciamento entre gestores, profissionais e o público alvo da política pública (SILVA, 2008).

\subsubsection{Criação de um serviço de acolhimento específico para crianças e adolescentes em situação de rua}

A necessidade de criação de um serviço específico para atendimento de crianças e adolescentes em situação de rua, em especial um serviço de acolhimento, encontra respaldo nas Resoluções $n^{o} 1$ de $2016^{13}$ e $n^{o} 1$ de $2017^{14}$ do CNAS e CONANDA. Ambas trazem em seu bojo as diretrizes, metodologias e orientações técnicas a serem adotadas pelo serviço de acolhimento para crianças e adolescentes em situação de rua.

\footnotetext{
${ }^{13}$ 4.6 Serviços de Acolhimento para crianças e adolescentes em situação rua: Os Serviços de Acolhimento para crianças e adolescentes em situação de rua devem contar com processos e diferenciais para atendimento desse público e não podem, de modo algum, constituírem-se espaços de estigmatização, segregação, isolamento, discriminação, não devendo possuir natureza de acolhimento compulsório, devendo favorecer, com ênfase e sempre que possível, o restabelecimento dos vínculos familiares e comunitários. Caso isto não possa ser realizado, deve-se buscar o encaminhamento para família substituta ou, ainda, o desenvolvimento da autonomia e a preparação gradativa para o desligamento e/ou para a vida adulta (BRASIL, 2016).

14 Art. $1^{\circ}$. Estabelecer as seguintes Diretrizes Políticas e Metodológicas para o atendimento de crianças e adolescentes em situação de rua no âmbito da Política de Assistência Social: [...] XIX - garantir o acesso da criança ou do adolescente em situação de rua a serviços de acolhimento, assegurando-se estratégias diferenciadas para o atendimento personalizado, considerando as especificidades e singularidades deste público (BRASIL, 2017).
} 
Ainda que o Plano Nacional de Promoção, Proteção e Defesa do Direito de Crianças e Adolescentes à Convivência Familiar e Comunitária aponte que os serviços de acolhimento institucional não devem ter público categorizado e que, portanto, devem ser universais, evitando-se assim estigmas para essas crianças (BRASIL, 2006), na prática, os serviços de acolhimento tradicionais (SAICA) não têm se mostrado adequados para o público infantojuvenil que se encontra em situação de rua. Isso porque, dadas as necessidades peculiares desse grupo, os serviços tradicionais possuem regras rígidas para a entrada, permanência e saída, o que acarreta no desligamento constante dos programas e na dificuldade de criação de vínculos com essa criança e/ou adolescente. De tal modo, trata-se de uma necessidade a criação de um serviço de acolhimento para crianças e adolescentes em situação de rua que contem com processos e diferenciais para atendimento desse público, não devendo possuir natureza de acolhimento compulsório.

No que tange à criação de um serviço de acolhimento específico para crianças e adolescentes em situação de rua de Ribeirão Preto, no âmbito do Projeto, profissionais que integram o GT identificaram a ausência desse serviço como um complicador na construção de uma rede completa e que atenda às demandas de maneira integral. Isso porque, as especificidades de um serviço de acolhimento dificilmente serão supridas por outros serviços da rede, sobretudo em se tratando da possibilidade de pernoite permanente ou esporádica.

\subsubsection{Ação em rede}

Por fim, a ação em rede mostra-se indispensável para a elaboração de uma política pública capaz de garantir e efetivar direitos de crianças e adolescentes em situação de rua. A impossibilidade, seja em termos pessoais ou materiais, de um único serviço dar conta de todas as demandas de crianças e adolescentes em situação de rua coloca-nos à frente da necessidade de uma ação e atuação intersetorial dos serviços. Nesse sentido, a criação e fortalecimento de fluxos entre os serviços constitui parte da estratégia intersetorial.

Nesse contexto, a Resolução Conjunta CNAS/CONANDA nº1 de 2017 tem o fortalecimento da intersetorialidade como uma das diretrizes políticas e metodológicas para o atendimento de crianças e adolescentes em situação de rua no que diz respeito à Política de Assistência Social. Em igual sentido, a Lei estadual nº 16.544/2017 elenca como um dos objetivos da Política Estadual de Atenção Específica para a População em Situação de Rua a criação de protocolos de articulação entre o SUAS e o SUS, indicando, pois, a necessidade de fluxos entre os serviços socioassistenciais e os serviços da área da saúde. Em âmbito do GT 
do Projeto, a necessidade de criação de fluxos e de fortalecimento daqueles já existentes para um atendimento integral e adequado de crianças e adolescentes em situação de rua do munícipio colocou-se constantemente enquanto uma questão a ser enfrentada a nível local.

Como um objetivo do próprio Projeto, a existência de um grupo, no qual tem sido possível a discussão, o debate e ações visando o atendimento de crianças e adolescentes em situação de rua local, tem se mostrado uma ferramenta para a construção de uma política pública baseada na ação em rede.

\section{CONCLUSÕES}

Ainda que o Projeto "Políticas públicas para crianças e adolescentes em situação de rua de Ribeirão Preto - SP", objeto do estudo de caso do presente trabalho, bem como a própria pesquisa estejam em andamento, é possível que algumas conclusões preliminares sejam elencadas. O surgimento e desenvolvimento de um Projeto que se propõe a dar visibilidade às crianças e adolescentes em situação de rua, ainda que a nível local, e a trazer ao debate público a necessidade de políticas públicas específicas para esse grupo, traz também consigo a discussão sobre os direitos de crianças e adolescentes em situação de rua.

Implica afirmarmos a necessidade de estabelecermos marcos normativos capazes de garantir direitos e responder a demandas de crianças e adolescentes em situação de rua. Nesse contexto, elencar pontos chaves para o estudo e elaboração de uma política pública para esse grupo se mostra relevante sob dois aspectos: de um lado, a elaboração de uma política pública que cumpra estritamente as formalidades e a legalidade exigidas para a elaboração e implementação de uma política pública; de outro lado, o desenho e execução de uma política que atenda às demandas de crianças e adolescentes e seja capaz de garantir e efetivar direitos de um grupo vulnerabilizado e constantemente alvo de violências.

\section{REFERÊNCIAS}

BRASIL [Constituição Federal (1988)]. Constituição da República Federativa do Brasil de 1988. Brasília, DF: Presidência da República [1988]. Disponível em:

http://www.planalto.gov.br/ccivil_03/constituicao/constituicao.htm. Acesso em: 21 fev. 2021.

BRASIL. Conselho Nacional dos Direitos da Criança e do Adolescente (Conanda). Plano Nacional de Promoção, Proteção e Defesa do Direito de Crianças e Adolescentes à Convivência Familiar e Comunitária. Brasília, DF, 2006. Disponível em: http://www.conselhodacrianca.al.gov.br/sala-deimprensa/publicacoes/PNCFC\%20_\%2028_12_06\%20_\%20Documento\%200ficial\%20_2_. pdf/view. Acesso em: 03 mar. 2020. 
BRASIL. Conselho Nacional de Assistência Social (CNAS); Conselho Nacional dos Direitos da Criança e do Adolescente (CONANDA). Resolução Conjunta $n^{\circ} 187$ de 23 de maio de 2017. Aprova o documento Orientações Técnicas para Educadores Sociais de Rua em Programas, Projetos e Serviços com crianças e adolescentes em situação de rua. Brasília, DF. Diário Oficial da União. Brasília, DF. Publicado em 30 de maio de 2017, edição 102, seção 1, página 107. Disponível em: https://www.in.gov.br/materia/-

/asset_publisher/Kujrw0TZC2Mb/content/id/20245348/do1-2017-05-30-resolucao-n-187-de23-de-maio-de-2017-20245088. Acesso em: 11 mar. 2020.

CARNEIRO, Carla Bronzo Ladeira. Programas de proteção social e superação da pobreza: concepções e estratégias de intervenção. 2005. Tese (Doutorado) - Faculdade de Filosofia e Ciências Humanas, Universidade Federal de Minas Gerais, Belo Horizonte, 2005.

FIORATI, Regina Célia; CARRETTA, Regina Yoneko Dakuzaku; KEBBE, Leonardo Martins; PANÚNCIO-PINTO, Maria Paula; CARDOSO, Beatriz Lobato. População em vulnerabilidade, intersetorialidade e cidadania: articulando saberes e ações. Saúde soc., São Paulo, vol. 23, n. 4, dez. 2014, p. 1458-1470.

FIORATI, Regina Célia; CARRETTA, Regina Yoneko Dakuzaku; KEBBE, Leonardo Martins; CARDOSO, Beatriz Lobato; XAVIER, Joab Jefferson da Silva. As rupturas sociais e o cotidiano de pessoas em situação de rua: um estudo etnográfico. Revista Gaúcha de Enfermagem, Porto Alegre, v.37, n.spe, 2016. Disponível em: http://dx.doi.org/10.1590/19831447.2016.esp.72861. Acesso em 28 de fev. de 2021.

GONTIJO, Daniela Tavares; MEDEIROS, Marcelo. Crianças e adolescentes em situação de rua: contribuições para a compreensão dos processos de vulnerabilidade e desfiliação social. Revista Ciência e Saúde Coletiva, vol.14, n.2, 2009, p.467-475.

INSTITUTO BRASILEIRO DE GEOGRAFIA E ESTATÍSTICA. Brasil, São Paulo, Ribeirão Preto. IBGE. [S.1.] [2019]. Disponível em https://cidades.ibge.gov.br/brasil/sp/ribeiraopreto/panorama. Acesso em: 02 mar. 2021.

LEITE, Bruno Rodrigues. A população em situação de rua e o mandado de segurança. São Paulo: Editora D’Plácido, 2017.

MELO, Eduardo Rezende. Crianças e adolescentes em situação de rua: direitos humanos e justiça. São Paulo: Malheiros, 2011.

ORGANIZAÇÃO DAS NAÇÕES UNIDAS. Comentário geral $n^{\circ} 21$ sobre crianças em situações de rua. [S.1.], 2017. Disponível em

https://bettercarenetwork.org/sites/default/files/GC\%20\%23\%2021\%20\%282017\%29_Street $\% 20$ Children.pdf. Acesso em 20 de mar. de 2021.

RIZZINI, Irene. Crianças e adolescentes em conexão com a rua: pesquisas e políticas públicas. Rio de Janeiro: Ed. PUC-Rio, 2019. 
; VALE, Juliana Batistuta; COUTO, Renata Mena Brasil do. Os desafios da implementação de políticas públicas para crianças e adolescentes em situação de rua: um guia comentado, $1^{\text {a }}$ ed., Rio de Janeiro: CIESPI, 2018.

SILVA, Rosemeire Barboza. O processo de organização política da população em situação de rua na cidade de São Paulo: limites e possibilidades da participação social. Anais do Seminário Nacional População em Situação de Rua: perspectivas e políticas públicas. Universidade Federal de São Carlos: 2008, p.87-97.

ZUFELATO, Camilo. Análise da judicialização das políticas públicas em prol dos direitos da população em situação de rua e dependentes químicos a partir do caso Cracolândia. In:

GRINOVER, Ada Pellegrini; ALMEIDA, Gregório Assagra de; GUSTIN, Miracy; LIMA, Paulo César Vicente de; IENNACO, Rodrigo. Direitos fundamentais das pessoas em situação de rua. São Paulo: Editora D’Plácido, 2016, p 515-537. 